\title{
Dynamic Characteristic of Ethanol Concentration Measurement System
}

\author{
Novitas Dwi Susanti ${ }^{*}$, Eko Joni Pristianto ${ }^{2}$, Ari Rahayuningtyas ${ }^{3}$, Diang Sagita $^{4 *}$, and Pamungkas Daud ${ }^{5}$ \\ ${ }^{1,3,4}$ Research Center for Appropriate Technology, Indonesian Institute of Sciences \\ Subang, Indonesia \\ ${ }^{2,5}$ Research Center for Electronics and Telecommunications, Indonesian Institute of Sciences, Indonesia \\ Bandung, Indonesia \\ *Corresponding author's email: ${ }^{1}$ novitadsanty [AT] gmail.com, ${ }^{2}$ diang.sagita [AT] gmail.com
}

\begin{abstract}
The design of the ethanol concentration measurement system using a specific gravity approach has been previously developed. It was built for batch distillation column automation. The measurement system use a combination of 2 kinds of sensor (i.e. load cell sensor and ultrasonic sensor). However, the dynamic characteristic of the measurement system has not been evaluated. This paper is a continuation of the previous paper. This paper aims to describe the dynamic characteristics of the ethanol concentration measurement system. The dynamic characteristic is another performance analysis besides the static characteristic that present in the previous paper. The dynamic characteristic covers rise time, settling time, and overshoot. This paper also presents a transfer function, pole, and zero location by process the output and input data. This paper concern about dynamic characteristics at one-point operation (75\% of ethanol measuring with a hydrometer) then measured by the ethanol measurement system that was designed in this research. Farther the dynamic characteristic was observed from the device until the device reading was steady-state. The result revealed that the rise time of ethanol concentration of measurement system was 56.4 second, settling time 112.2 second and percentage of overshoot was $1.2 \%$. The measurement system can present the actual data after 117.4 second.
\end{abstract}

Keywords- Dynamic characteristic, ethanol concentration, overshoot, rise time, settling time

\section{INTRODUCTION}

The ethanol concentration measurement system was built to measure the ethanol concentration value at batch distillation column automation. This measurement system uses a specific gravity approach to measure the concentration value [1]. The fundamental principles of the system are to measure the mass and the volume of the ethanol by using a load cell sensor and ultrasonic sensor respectively. Then, the data is combined to get specific gravity. Measurement is a process to compare the unknown value with standard value [2]. In this research, the unknown value was ethanol concentration value while the standard value was reading by hydrometer.

According to Pallas-Areny $\mathrm{R}$ and Webster [3] and Weber [4], there are static characteristics and dynamic characteristics that can show the performance of a measurement system. Static characteristic was presented in Susanti et al. [1] and this paper focus on the dynamic characteristic.

Dynamic characteristic was described as an unknown value that reading by measurement system and changed with time [5]. The characteristic of the measurement system should be known. It is important for the user to choose the application and to know the performance of the measurement system. In this research, the reference uses hydrometer as a comparative device to measure ethanol concentration value.

Response time is one of the dynamic characteristics in the measurement system that covers rise time and settling time. Overshoot also described in this research as a dynamic characteristic [6]. Finally, we can get the transfer function and look for stability analysis according to the pole and zero position [7].

A transfer function is a mathematically function modeling between output and input stimulus. From this modeling, we can get the output response. Also, the pole and zero location so the measurement system can analyze the stable and unstable conditions. 


\section{THEORY AND FORMULA}

Dynamic characteristic is a measurement system response based on time. In this research, it covers rise time, settling time, and overshoot. This response can see from the output signal. Rise time is the response time from 10\% until $90 \%$ before steady-state. Settling time is a beginning response until $5 \%$ before steady-state. Overshoot is a signal response exceeding the steady-state and then back to steady-state [6].

The dynamic system analysis determined at one-point operation at $75 \%$ alcohol measured by hydrometer and it was tested with the developed measurement system.

The stability system in a dynamic system near equilibrium point usually describing by Lyapunov stability. Actually the nonlinear system has to propose a candidate equation to determine the Lyapunov stability. In this paper, an indirect way was used to determine stability. There is linearity at one-point operation or determine the transfer function at onepoint operation at a discrete-time [8].

To determine the stability of the system, we can see the location of the pole and zero. There is asymptotic stability where the Eigenvalue position in the unit circle if the Eigenvalue outside the unit circle the system was unstable, and if the Eigenvalue strictly at the unit circle, the system marginally stable [8].

\section{EXPERIMENTAL SETUP}

This experiment uses the ethanol measurement system developed previously by Susanti et al. [1]. The components of the device can be seen in Fig. 1. The ethanol concentration measurement system was tested at one sample operation (i.e. $75 \%$ ), then the responses were analyzed. The parameter analyzed was the dynamic characteristics of the measurement system that consist of rise time, settling time, and overshoot. The data was recorded by the system and stored on the memory card. Then, the data was analyzed in the spreadsheet data processing.

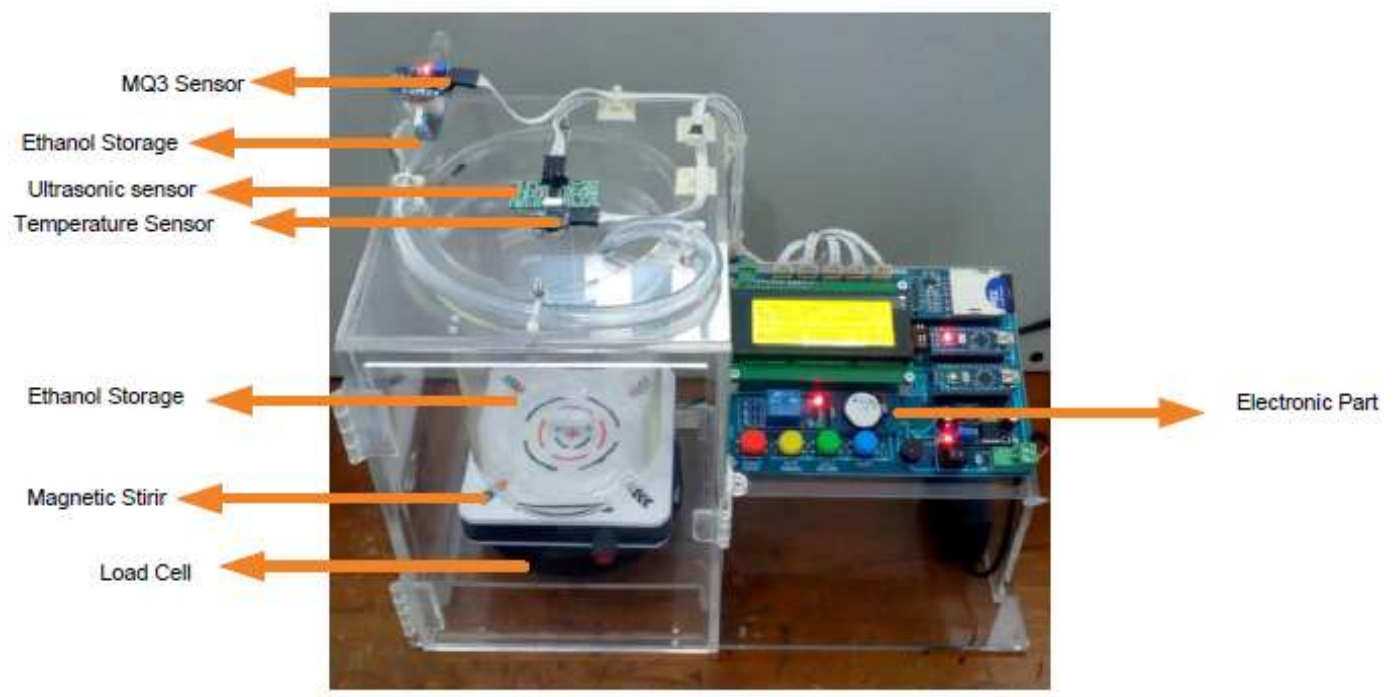

Figure 1: The component of the ethanol concentration measurement system [1]

\section{RESULT AND DISCUSSION}

Fig. 2 show the response of the ethanol concentration measurement system. From the curve, before the steady-state reading of the measurement system, there is a slope. The slope consists of rise time, settling time and overshoot. 


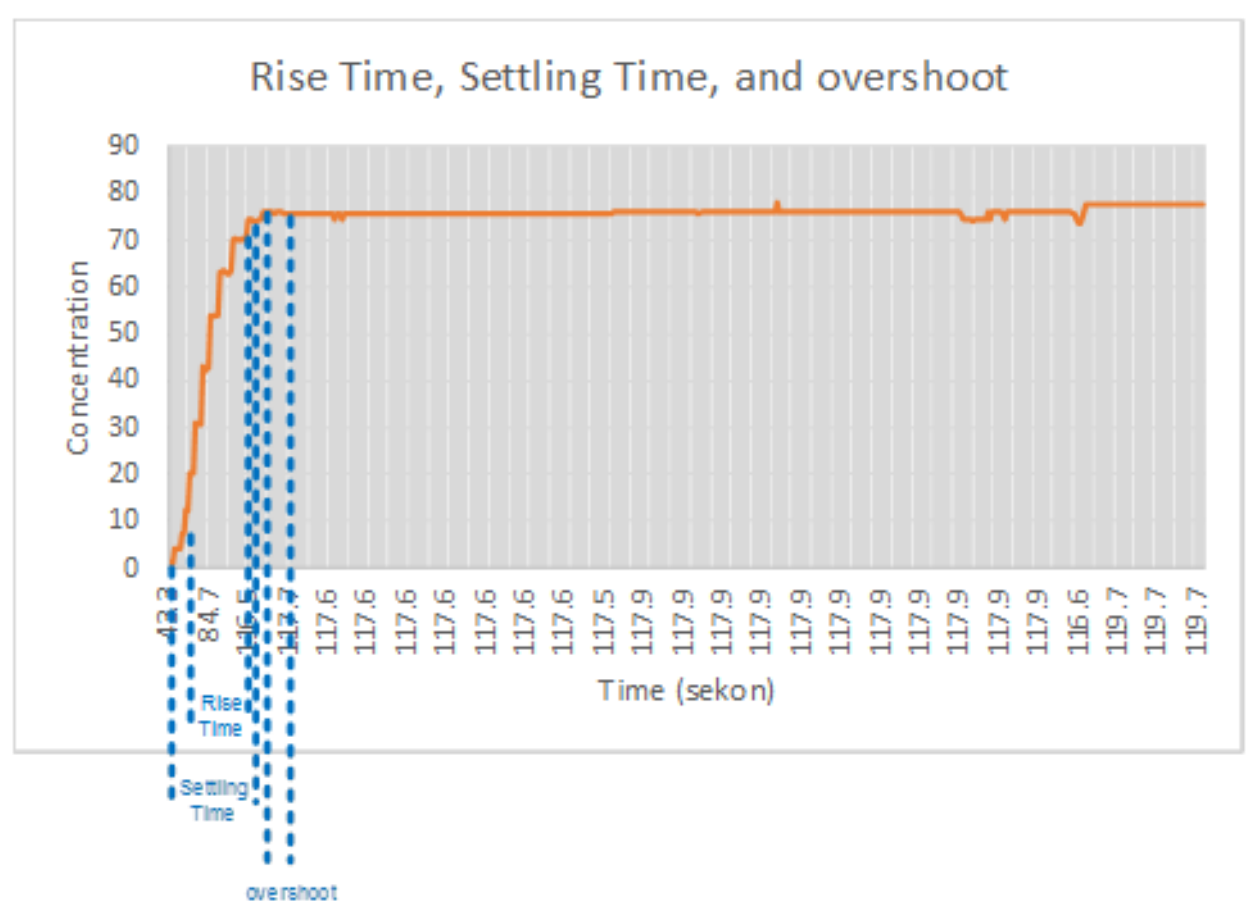

Figure 2: The response of ethanol concentration measurement system

The result had shown similar characteristics described by Baksi [6] where rise time is the response time from $10 \%$ until $90 \%$ before steady-state. Settling time is a beginning response until $5 \%$ before steady-state and overshoot is a signal response exceeding the steady-state and then back to steady-state. From Fig. 2, the detail data of rise time, settling time and overshoot is shown in Table 1.

Table 1: Dynamic characteristic of the measurement system

\begin{tabular}{ccc}
\hline Parameter & Value & Unit \\
\hline Rise time & 56.4 & $\mathrm{~s}$ \\
Settling time & 112.2 & $\mathrm{~s}$ \\
Overshoot & 1.2 & $\%$ \\
\hline
\end{tabular}

Table 1 shown the rise time of ethanol concentration of measurement system is 56.4 second, settling time 112.2 second and percentage overshoot is $1.2 \%$. Overall, the measurement system can present the actual data after 117.4 seconds. This measurement is relatively quick due to the result can be obtained about 2 minutes with high accuracy. Furthermore, the system was also stable in the sense the Lyapunov stability.

The transfer function and location of pole and zero are described by using Matlab and the data input and output can be seen in Fig. 3. The transfer function in the $\mathrm{z}$ domain is shown in the following equation.

$$
\frac{0.006788 z^{-1}}{1-1.863 z^{-1}+0.8703 z^{-2}}
$$

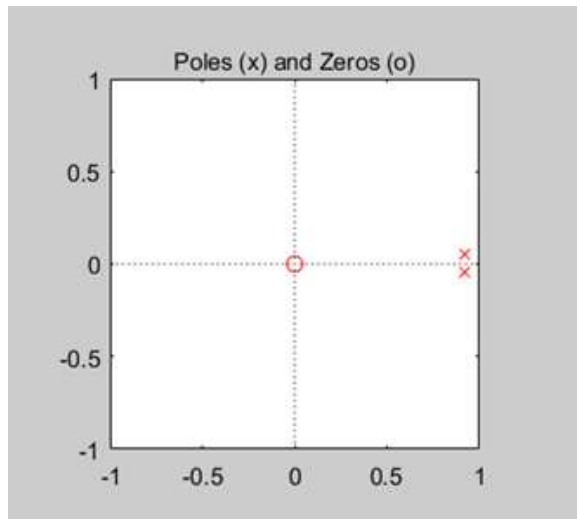

Figure 3: Location of pole and zero 


\section{CONCLUSION}

The measurement system beside static characteristics has dynamic characteristics. The ethanol concentration measurement system that has been developed has several dynamic characteristics, i.e. 56.4 seconds of rise time, 112.2 seconds of settling time, and has $1.2 \%$ of overshoot. The measurement system can present the actual data after 117.4 seconds. The system was also stable in the sense the Lyapunov stability.

\section{ACKNOWLEDGEMENT}

The authors want to thanks to the Research Center for appropriate technology - Indonesian Institute of Sciences, Bandung Institute of Technology, and all of the colleague to finish my thesis and write the second paper from this thesis.

\section{REFERENCES}

[1] Susanti N D, Rahman A S, and Pristianto E J, "Design of ethanol concentration measurement system using specific gravity approach for batch distillation column automation”, In The International Conference on Radar, Antenna, Microwave, Electronics, and Telecommunication, pp. 148-151, 2019.

[2] Gutierrez-Osuna R, "Intelligent sensor system. Wright State University", 2002. Available at: http://research.cs.tamu.edu/prism/lectures/iss/iss_114.pdf

[3] Pallas-Areny R and Webster J G, "Sensors and Signal Conditioning”, New York: Wiley, 1991.

[4] Webster J G, "The Measurement, Instrumentation and Sensors Handbook", Boca Raton, Florida: CRC/IEEE Press, 1999.

[5] Morris A S, "Measurement and Instrumentation Principle", Oxford: Butterworth-Heinemann, 2001.

[6] Baksi S, "Characteristic of Instrument: Static and Dynamic", Available at: https://learnmechanical.com/static-anddynamic-characteristic-of-instrument/

[7] Ogata K, "Modern Control Engineering 6th Edition", New Jersey: Prentice Hall, 2010.

[8] Mahayana D, “Kestabilan System Non linier”, Bandung: ITB Press, 2019. 